\title{
microRNA-10b expression and its correlation with molecular subtypes of early invasive ductal carcinoma
}

\author{
CHENMING GUO, MINGGANG FU, YILAMU DILIMINA, SHA LIU and LIYING GUO \\ Department of Breast Cancer, Digestive and Vascular Center, \\ The First Affiliated Hospital of Xinjiang Medical University, Urumqi, Xinjiang 830054, P.R. China
}

Received September 19, 2016; Accepted July 18, 2017

DOI: 10.3892/etm.2018.5797

\begin{abstract}
The present study aimed to determine whether the expression of microRNA (miR)-10b was correlated with the molecular subtypes of early invasive ductal carcinoma of the breast. In situ hybridization was used to detect the expression of miR-10b in 193 patients diagnosed with early invasive ductal carcinoma. Immunohistochemistry was performed to evaluate the expression of estrogen receptor (ER)- $\alpha$, progesterone receptor (PR) and human epidermal growth factor receptor-2 (Her-2). The positive expression rate of miR-10b in patients with early invasive ductal carcinoma with ER- $\alpha(+)$ or PR (+) was decreased compared with ER- $\alpha$ $(-)$ or PR $(-)$ patients $(\mathrm{P}<0.05)$. Furthermore, the positive expression rate of miR-10b in patients with Her-2 (-) was significantly increased compared with patients that were Her-2 (+) $(\mathrm{P}=0.031)$. The positive expression rate of $\mathrm{miR}-10 \mathrm{~b}$ in the luminal B subtype was significantly decreased compared with that in the luminal A, Her-2 and basal-like subtypes $(\mathrm{P}=0.037)$. In patients that were identified as miR-10b $(+)$, the median disease-free survival time was significantly increased in patients that were ER- $\alpha(+) / \mathrm{PR}(+) / \mathrm{Her}-2(-)$ compared with patients that were ER- $\alpha(-) / \mathrm{PR}(-) / \mathrm{Her}-2(+)(\mathrm{P}<0.05)$. In addition, the median disease-free survival time was significantly decreased in Her-2 overexpression and basal-like subtypes when compared with luminal A and B subtypes $(\mathrm{P}<0.05)$. The molecular subtype was an independent prognostic factor for early invasive ductal carcinoma (odds ratios for luminal B,
\end{abstract}

Correspondence to: Dr Liying Guo, Department of Breast Cancer, Digestive and Vascular Center, The First Affiliated Hospital of Xinjiang Medical University, 137 South Liyushan, Urumqi, Xinjiang 830054, P.R. China

E-mail: gejsy318@126.com

Abbreviations: ER- $\alpha$, estrogen receptor- $\alpha$; PR, progesterone receptor; Her-2, human epidermal growth factor receptor-2; miRNA/miR, microRNA; ISH, in situ hybridization; FISH, fluorescence in situ hybridization; DAB, 3,3'-diaminobenzidine; OR, odds ratio

Key words: early breast invasive ductal cancer, microRNA-10b, molecular subtypes
Basal-like, and Her-2 overexpression were 2.900, 5.232 and 4.214 , respectively; all $\mathrm{P}<0.05$ ). Positive expression of miR-10b may also be a prognostic risk factor (odds ratio $>1$ ), though this was not statistically significant $(\mathrm{P}>0.05)$. The present findings indicated that miR-10b-positive expression was correlated with the expression of ER- $\alpha$, Her- 2 and the molecular subtypes of early invasive ductal carcinoma of the breast.

\section{Introduction}

The majority of early invasive ductal carcinomas are diagnosed by pathological biopsy $(1,2)$. However, patients presenting with the same clinical pathological stage that receive similar clinical treatments may have distinct prognoses $(3,4)$. Due to the heterogeneity of breast cancer, the molecular subtype theory has been proposed, which suggests that breast cancer should be divided into four subtypes based on differential molecular expression $(5,6)$. For instance, the luminal A subtype of invasive ductal carcinoma accounts for $65 \%$ of all breast cancer cases, and typically occurs in postmenopausal women (7). The maximum tumor diameter of the luminal A subtype is $<2 \mathrm{~cm}$. Luminal A, namely the estrogen receptor (ER)- $\alpha(+) /$ progesterone receptor (PR) (+)/Human epidermal growth factor receptor-2 (Her-2) (-)/low expression of Ki-67, is the most common subtype that accounts for $50 \%$ of all subtypes (8). In addition, luminal A subtype breast cancer has the lowest rate of recurrence and metastasis (9). Her-2 overexpression is a subtype of breast cancer that accounts for 20-30\% of breast cancer cases (6), while the triple-negative subtype [Her-2 (-), ER (-) and PR (-)] accounts for $11-17 \%$ of cases (10). Furthermore, Her-2 overexpression and triple-negative breast cancer typically occur in pre-menopausal women $(9,11)$. The tumor diameters associated with the Her-2 and triple-negative subtypes are $>2 \mathrm{~cm}(12,10)$, and the recurrence rate for tumors with diameter $>2 \mathrm{~cm}$ is relatively high (12). As the fourth subtype, basal-like type breast cancer has been associated with a familial genetic tendency, and has the highest rates of recurrence and metastasis compared with other subtypes (10).

MicroRNA (miRNA/miR) and its relevant signaling pathways may be associated with the recurrence, metastasis and prognosis of early invasive ductal carcinoma of the breast, along with the efficacy of treatment $(13,14)$. For instance, Lowery et al (15) reported that levels of miRNA expression were positively correlated with the expression of ER- $\alpha, P R$ 
and Her-2. Furthermore, previous studies have indicated that miR-10b was involved in early-stage breast invasive ductal carcinoma $(16,17)$. Overexpression of miR-10b has also been observed in breast cancer cells with high metastatic capability, and has been implicated in the regulation of breast cancer metastasis (18). In addition, miR-10b may enable non-metastatic breast cancer tumor cells to acquire potent invasive and metastatic properties (19).

In the present study, the expression of miR-10b was detected using in situ hybridization (ISH) in tumor samples of patients with early invasive ductal carcinoma of the breast. Immunohistochemistry was also performed to evaluate the expression of ER- $\alpha$, PR and Her- 2 in the tumor samples. Based on the levels of ER- $\alpha$, PR and Her-2 expression, patient specimens were further classified into different molecular subtypes, and the associations between miR-10b expression with the expression of ER- $\alpha$, PR and Her- 2 and the molecular subtypes were analyzed.

\section{Materials and methods}

Clinical data of patients. A database was established for patients with breast cancer, which contained the data of 2,600 patients who received treatment at the First Affiliated Hospital of Xinjiang Medical University (Urumqi, China) between January 2000 and December 2013. In the database, all patients with breast cancer were pathologically confirmed (20), and their clinical data and follow-up information were complete. The follow-up data was collected for 2-15 years post-operation via outpatient clinics, return visits and telephone interviews. The interval of follow-up study was 1 year and the deadline was December 2015. A lack of tumor recurrence during the follow-up period was regarded as disease-free survival. Imaging (abdominal ultrasound, bone scan, lung computed tomography) and histopathological examining of tissues were used to confirm tumor metastases and recurrence. The loss to follow-up rate was $6 \%$. In the present study, 193 patients with early invasive ductal carcinoma of the breast were selected from the database. Patients were excluded if they: i) had other cancers; ii) received preoperative radiotherapy, chemotherapy; and iii) had non-breast-derived early breast invasive ductal carcinoma. The tumor diameter of enrolled patients was $\leq 2 \mathrm{~cm}$. All of the patients were women aged 34-78 years old (mean age, 46.5 years old). Tumor samples were collected from the patients with early invasive ductal carcinoma during radical surgery. All tumor samples were sectioned into size of $1 \times 1 \times 0.5 \mathrm{~cm}$, and subjected to immersion fixation with $10 \%$ neutral buffered formalin for $24 \mathrm{~h}$ at $4^{\circ} \mathrm{C}$. Samples were then embedded in paraffin. Prior written informed consent was obtained from all patients and the study was approved by the Ethics Review Board of the Ethics Committee of Xinjiang Medical University.

ISH. The enhanced sensitivity of an ISH detection kit I (Boster Biological Technology, Pleasanton, CA, USA) was used to perform an in situ hybridization assay. A hsa-miR-10b miRCURY LNA Detection Probe was purchased from Exiqon A/S (Vedbaek, Denmark). All procedures were performed following the manufacturer's instructions. Paraffin slices of
$4 \mu \mathrm{m}$ of tumor samples from 193 patients with early invasive ductal carcinoma were deparaffinized with xylene and dehydrated with ethanol, and subsequently treated with $3 \% \mathrm{H} 2 \mathrm{O} 2$, washed by distilled water twice, combined with $3 \%$ citric acid and two drops of concentrated pepsin according to the instructions of the kit (cat. no. MK1030; Boster Biological Technology, Pleasanton, CA, USA). Following washing with phosphate buffered saline (PBS) three times and distilled water once, sample slices were prehybridized with digoxigenin-labeled oligonucleotide probes $(40 \mathrm{nM})$ at $37^{\circ} \mathrm{C}$ in a wet box for $3 \mathrm{~h}$. Slices were then washed with PBS for 2 times and incubated with $20 \mu 1$ digoxigenin-labeled oligonucleotide probes overnight at $37-40^{\circ} \mathrm{C}$. Following washing with PBS three times, $1 \mathrm{X}$ biotinylated mouse anti-digoxin was added to slices for a further $2 \mathrm{~h}$ incubation at $4^{\circ} \mathrm{C}$. Slices were respectively incubated with streptavidin biotin complex and biotinylated peroxidase (3\%) for $30 \mathrm{~min}$ at $37^{\circ} \mathrm{C}$. Finally, 3,3'-diaminobenzidine (DAB) was used for color development, and samples were counterstained with hematoxylin. Slices were mounted and observed under a light microscope (Olympus Corporation, Tokyo, Japan). Cells with brown staining in the cytoplasm were defined as miR-10b-positive cells. According to the color intensity and number of positive cells, staining scores were assigned, as described previously (21). Briefly, cells expressing miR-10b were scored based on the degree of staining, as follows: 0 points, no color; 1 point, yellowish, 2 points, brownish-yellow; and 3 points, brown. According to the number of positive cells, the expression of miR-10b was classified into four conditions: Score 1 , the rate of positive cells was $1-25 \%$; score 2 , the rate of positive cells was $26-50 \%$; score 3 , the rate of positive cells was $51-75 \%$; and score 4 , the rate of positive cells was $>75 \%$. The final evaluation score for miR-10b expression in each sample was calculated as follows: Final score $=$ score of color intensity $\mathrm{x}$ score of positive cell rate. In addition, the final score was divided into four expression categories: $0,(-) ; 1-2$ points, (+); 3-4 points $(++)$; and $>4$, points $(+++)$.

Immunohistochemistry. Immunohistochemistry was performed using an immunohistochemistry kit (cat. no. SV00002; Boster Biological Technology) according to the manufacturer's instructions. Paraffin slices of $4 \mu \mathrm{m}$ of tumor samples were deparaffinized and dehydrated. Following the position of the antigen was detected by probes, slices were processed with peroxidase blocking solution (3\%) and incubated at $37^{\circ} \mathrm{C}$ for $10 \mathrm{~min}$ with $5 \%$ bovine serum to block non-specific antigens. A total of $50 \mu 1$ primary antibody was added to slices and incubated for $30 \mathrm{~min}$ at room temperature. The primary antibodies used were rabbit anti-ER- $\alpha$ monoclonal antibody (ab16660; 1:100), rabbit anti-PR monoclonal antibody (ab32085; $1: 100)$ and rabbit anti-Her-2 monoclonal antibody (ab134182; 1:100), which were purchased from Abcam (Cambridge, MA, USA). Following washing with phosphate-buffered saline, $50 \mu \mathrm{l}$ horseradish peroxidase-conjugated goat anti-rabbit antibody (cat. no. SV00002; 1:200; Boster Biological Technology) was added to the slices and incubated for 10-15 min at room temperature. Subsequently, $100 \mu 1$ DAB was added for color development. Following washing, slices were counterstained with hematoxylin, mounted with neutral gum and observed under an upright light microscope (BX43; Olympus Corporation). 
The expression levels of ER- $\alpha$ and PR were defined according to the American Society of Clinical Oncology criteria (22). When the rate of positive tumor cells was $\leq 10 \%$, samples were considered as ER- $\alpha$ or PR-negative, while those with a rate $>10 \%$ were considered as ER- $\alpha$ or PR positive. To define the expression levels of Her-2, the Hercep test standard was used (22), as recommended by the US Food and Drug Inspection Bureau. The expression of Her-2 was divided into four levels: $(-), \leq 10 \%$ cell membrane was positively stained; $(+),>10 \%$ cells were positively stained, but cells were not contiguous or surrounding the cell membrane; $(++),>10 \%$ cells were positively stained with a weak or moderate color surrounding the cell membrane and continuous; and (+++), $>10 \%$ cells were intensively and continuously stained around the cell membrane. When the immunohistochemical staining indicated Her-2 (+++) and the FISH test had confirmed Her-2 gene amplification, the sample was considered to exhibit high expression of Her-2.

Fluorescence ISH (FISH). Tumor specimens from all patients were embedded in paraffin and cut into $4-\mu \mathrm{m}$ thick sections. Following deparaffinization and dehydration, sections were immersed in $30 \%$ acidic sodium sulfite at $50^{\circ} \mathrm{C}$ for $30 \mathrm{~min}$. Following washing with saline-sodium citrate buffer, samples were digested using $5 \mu \mathrm{g} / \mathrm{ml}$ proteinase $\mathrm{K}$ solution (cat. no. 90003; Exiqon, Vedbaek, Denmark) for $4-10 \mathrm{~min}$ at $37^{\circ} \mathrm{C}$ and immersed in $0.1 \mathrm{M} \mathrm{HCl}$ for 5-10 min. Following fixation with $100 \%$ acetone for $10 \mathrm{~min}$ at $4^{\circ} \mathrm{C}$ and air-drying, the tumor samples were hybridized with $10 \mu 130 \mathrm{nM}$ probe-mixed solution (GLP HER-2/CSP17 dual-color fluorescent probes, cat. no. D3571; Thermo Fisher Scientific, Inc., Waltham, MA, USA) overnight in a wet box at $40^{\circ} \mathrm{C}$. Slices were air-dried in the dark following washing with saline-sodium citrate five times for $5 \mathrm{~min}$, and 4',6-diamidino-2-phenylindole was subsequently used to stain the nucleus. Slices were mounted and observed using fluorescence microscopy. The fluorescent probes GLP HER-2/CSP17 included two types of probes: CSP17 labeled the centromere of the chromosome 17 with green fluorescence, and HER-2 labeled the Her-2 gene with orange fluorescence. In each visual field (selected according to the results of immunohistochemical staining), 30 cells were counted. The fluorescence ratio was calculated using the following formula: Ratio $=$ number of cells (orange)/number of cells (green). When the ratio was $<1.8$, the sample was considered to exhibit Her-2-negative expression, which indicated no Her-2 amplification in the tumor sample. If the ratio was $>2.2$, the sample was regarded to exhibit Her-2-positive expression, which indicated that the Her-2 gene was amplified in the tumor sample. When the ratio was 1.8-2.2, more tumor cells were required to be counted or the FISH assay was repeated. If the ratio was $>20$ or there was contiguous fluorescence within clusters, this was considered to indicate gene amplification (23).

Statistical analysis. SPSS v17.0 statistical software (SPSS, Inc., Chicago, IL, USA) was used for data analysis. A Pearson's $\chi^{2}$ test was used to analyze the differential expression of miR-10b in patients with distinct expression of ER- $\alpha$, PR and Her-2. The Kaplan-Meier method was used to determine the cumulative disease-free survival time and a Log-rank test was performed to further analyze differences. A multivariate Cox regression model was applied to study different prognostic factors for early invasive ductal carcinoma. The menstruation status was measure according to if menopause was confirmed or not; the pathological grades (I or II) were determined according the (American Joint Committee on Cancer criteria; and treatment of chemotherapy and radiotherapy was determined as received (yes) or never received (no). $\mathrm{P}<0.05$ was considered to indicate a statistically significant difference.

\section{Results}

Determination of miR-10b expression. To determine the expression levels of miR-10b, in situ hybridization was performed. The positivity or negativity was determined by the cytoplasmic staining and miR-10b (+) cells were stained brown. The negative and positive expression of miR-10b was indicated in Fig. 1. Based on staining intensity and the percentage of positive cells, the expression levels of miR-10b were divided into negative expression (-) (Fig. 1A), weak positive expression (+) (Fig. 1B), positive expression (++) (Fig. 1C), and strong positive expression (+++) (Fig. 1D), respectively. Of all 193 included patients, 152 were miR-10b (+) and 41 were miR-10b (-) (Table I).

Determination of ER- $\alpha$ and $P R$ expression. To detect the expression levels of ER- $\alpha$ and PR, immunohistochemistry was performed. From the 193 patients, 110 were ER- $\alpha(+), 83$ were ER- $\alpha(-), 133$ were PR (+) and 60 were PR (-) (Table I). Fig. 2 depicts representative staining images of tumor samples obtained from patients. Tumor samples with a positive staining rate of $\leq 10 \%$ (ER- $\alpha$ - or PR-negative; Fig. 2A and C) and $>10 \%$ (ER- $\alpha$ - or PR-positive; Fig. $2 B$ and D) were identified.

Determination of Her-2 expression using immunohistochemistry and FISH. Her-2 expression was evaluated using immunohistochemistry and FISH. There were 71 patients that were Her- 2 positive patients and 122 that were Her-2 negative (Table I). Fig. 3A depicts a representative tumor sample with Her-2 (-) expression, while Figs. 3B-D represent Her-2 $(+),(++),(++)$ and $(+++)$ samples, respectively. Amplification of the Her-2 gene was detected using FISH. Fig. 3 depicts representative FISH images of tumor samples. Samples with a fluorescence ratio of $<1.8$ were considered to lack Her-2 expression, thus indicating that the Her-2 gene was not amplified in the tumor samples (Fig. 3E). A ratio of $>2.2$ identified samples as Her-2-positive, which indicated that the Her-2 gene was amplified in the tumor sample (Fig. 3F).

miR-10b expression and its correlation with the expression of $E R-\alpha, P R$ and Her-2 in early invasive ductal carcinoma. The association between miR-10b expression and the expression of ER- $\alpha$, PR or Her- 2 in 139 cases of early invasive ductal carcinoma was analyzed using a Pearson's $\chi^{2}$ test. From the total 193 patients, there were 54 patients who showed normal-like results in the immunohistochemistry test and were therefore not categorized into the four subtypes, hence they were not 
Table I. Relationship between miR-10b expression and ER- $\alpha$, PR and Her-2 expression in early breast invasive ductal cancer.

\begin{tabular}{|c|c|c|c|c|c|}
\hline Clinical indicator & $\mathrm{N}$ & miR-10b (-) (\%) & miR-10b (+) (\%) & $\chi^{2}$ & P-value \\
\hline \multicolumn{6}{|l|}{$\mathrm{ER}-\alpha$} \\
\hline$(+)$ & 110 & $29(26.4)$ & $81(73.6)$ & 4.008 & 0.045 \\
\hline$(-)$ & 83 & $12(14.5)$ & $71(85.5)$ & & \\
\hline \multicolumn{6}{|l|}{ PR } \\
\hline$(+)$ & 133 & $24(18.0)$ & $109(82.0)$ & 2.616 & 0.106 \\
\hline$(-)$ & 60 & $17(28.3)$ & $43(71.7)$ & & \\
\hline \multicolumn{6}{|l|}{ Her-2 } \\
\hline$(+)$ & 71 & $21(29.6)$ & $50(70.4)$ & 4.663 & 0.031 \\
\hline$(-)$ & 122 & $20(16.4)$ & $102(83.6)$ & & \\
\hline
\end{tabular}

miR-10b, microRNA-10b; ER- $\alpha$, estrogen receptor- $\alpha$; PR, progesterone receptor; Her-2, human epidermal growth factor receptor-2.

analyzed. Results indicated that the positive expression rate of miR-10b was significantly increased in ER- $\alpha(-)$ samples when compared with ER- $\alpha(+)$ samples $\left(\chi^{2}=4.008, \mathrm{P}=0.045\right.$; Table I). Similarly, in tumor samples that were Her-2 (-), the positive expression rate of miR-10b was significantly increased when compared with Her-2 (+) samples $\left(\chi^{2}=4.663, \mathrm{P}=0.031\right.$; Table I). By contrast, the miR-10b-positive expression rate was greater in tumor samples that were PR $(+)$ compared with those that were PR (-), though this was not statistically significant $\left(\chi^{2}=2.616, P=0.106\right.$; Table I $)$. These results indicate that the positive expression rate of miR-10b was negatively correlated with the expression of ER- $\alpha$ and Her-2.

miR-10b expression and its correlation with different molecular subtypes. Based on the expression of ER- $\alpha, P R$ and Her-2 in 139 patients with early invasive ductal carcinoma, the patients were divided into molecular subtypes, namely luminal A, luminal B, Her-2 overexpression and basal-like, as indicated in Table II. Among these distinct molecular subtypes, the positive expression rate of miR-10b in luminal B was significantly decreased when compared with the other subtypes $\left(\chi^{2}=8.250, \mathrm{P}=0.037\right.$; Table III $)$. This data indicates that positive expression of miR-10b may promote an increased risk of recurrence and metastasis of luminal B type breast cancer.

Survival analysis of patients with early invasive ductal carcinoma with miR-10b (+) expression and variable ER- $\alpha$, $P R$ and Her-2 expression. Cumulative disease-free survival analysis was performed using the Kaplan-Meier method and Log-rank test. In tumor samples that were identified as miR-10b (+), the median disease-free survival $(50 \%$ of the cumulative survival rate) time was significantly increased in patients that were ER- $\alpha(+)$ (11.466 years) compared with patients that were ER- $\alpha(-)$ (9.994 years; $\chi^{2}=4.375, \mathrm{P}=0.036$; Fig. 4). Similarly, the median disease-free survival free time was increased in patients that were miR-10b (+) and PR (+) (11.509 years) when compared with patients that were PR (-) (9.773 years; $\chi^{2}=2.883, P=0.090 ;$ Fig. 5). Conversely, in patients that were miR-10 (+) and Her-2 (-), the median disease-free survival time was 11.346 years, which was
Table II. Molecular subtypes of breast cancer and their receptor expression.

\begin{tabular}{ll}
\hline Molecular subtype & \multicolumn{1}{c}{ Receptor expression } \\
\hline Luminal A & ER- $\alpha(+)$, and/or PR (+), Her-2(-) \\
Luminal B & ER- $\alpha(+)$, and /or PR (+), Her-2(+) \\
Her-2 overexpression & ER- $\alpha(-)$, PR (-), Her-2 (+) \\
Basal-like & ER- $\alpha(-)$, PR (-), Her-2 (-) \\
\hline
\end{tabular}

ER- $\alpha$, estrogen receptor- $\alpha$; PR, progesterone receptor; Her-2, human epidermal growth factor receptor-2.

Table III. Association between miR-10b expression and early breast invasive ductal cancer molecular subtypes.

\begin{tabular}{lrrrc}
$\begin{array}{l}\text { Molecular } \\
\text { subtype }\end{array}$ & $\mathrm{N}$ & \multicolumn{1}{c}{$\begin{array}{c}\text { miR-10b } \\
(-)(\%)\end{array}$} & $\begin{array}{c}\text { miR-10b } \\
(+)(\%)\end{array}$ & P-value \\
\hline Luminal A & 52 & $7(13.5)$ & $45(86.5)$ & $0.037\left(\chi^{2}=8.25\right)$ \\
Luminal B & 35 & $13(37.1)$ & $22(62.9)$ & - \\
Her-2 & 20 & $3(15.0)$ & $17(85.0)$ & - \\
Basal-like & 32 & $4(12.5)$ & $28(87.5)$ & - \\
\hline
\end{tabular}

miR-10b, microRNA-10b; ER- $\alpha$, estrogen receptor- $\alpha$; PR, progesterone receptor; Her-2, human epidermal growth factor receptor-2.

significantly increased compared with patients that were Her-2 (+) (9.481 years) $\left(\chi^{2}=4.704, P=0.030\right.$, Fig. 6). For patients with miR-10b (-), miR-10b (-) expression had no effect on the median disease-free survival time of different breast cancer molecular subtypes (data not shown). These results suggest that miR-10b-positive expression resulted in different expression levels of PR, which has no significant effect on the disease-free survival curve of patients; however, for miR-10b-positive expression, different expression levels of ER- $\alpha$ and Her-2 may have a significant effect on the disease-free survival curve of patients. 

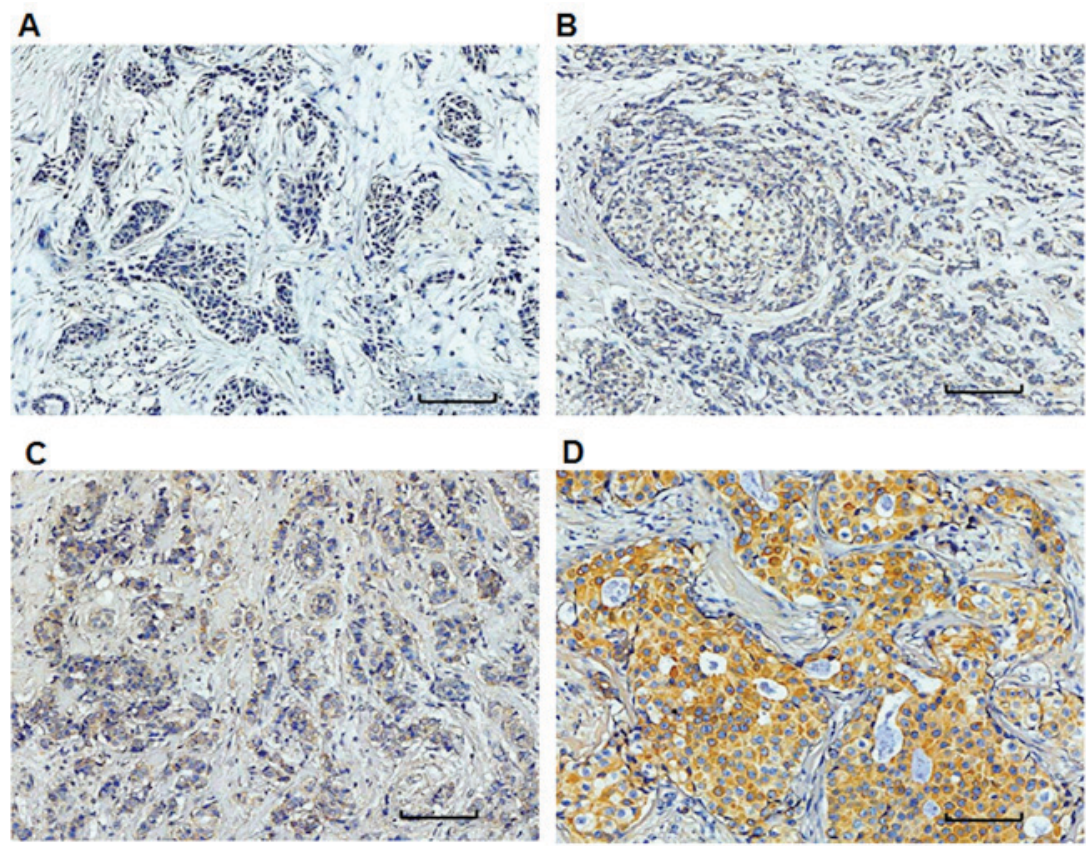

Figure 1. Expression of miRNA-10b in patients with early invasive ductal carcinoma detected by in situ hybridization. miRNA-10b-positive cells were identified by brown staining in the cytoplasm. Representative images with different staining degrees are shown. Magnification, x200. (A) 0 point (-), (B) 1-2 points (+), (C) 3-4 points (++) and (D) >4 points, (+++). miRNA-10b, microRNA-10b. Scale bar, $100 \mu \mathrm{m}$.

A

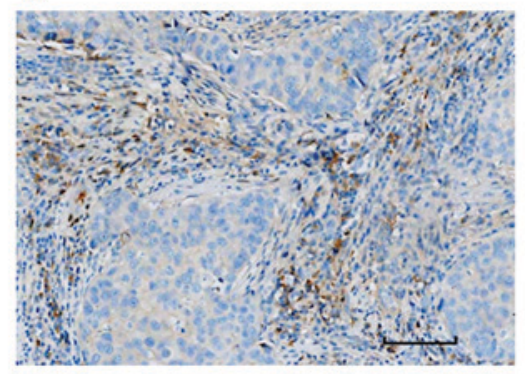

C

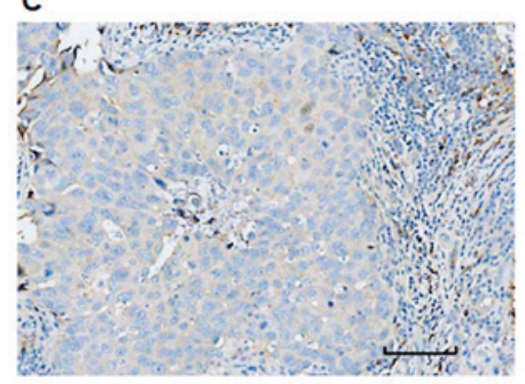

B

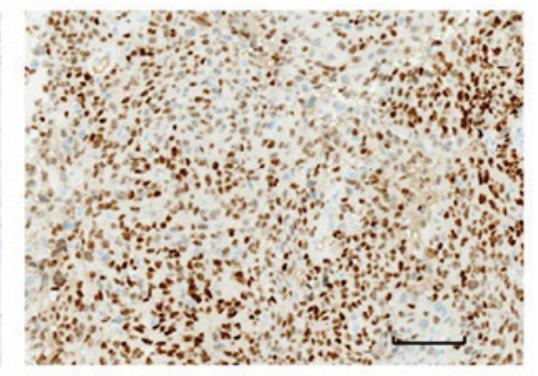

D

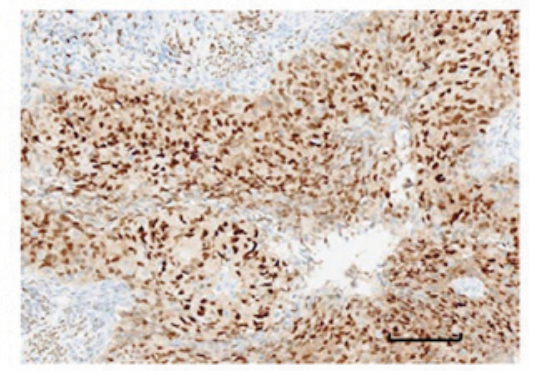

Figure 2. Expression of ER- $\alpha$ and PR in patients with early invasive ductal carcinoma detected by immunohistochemical staining. Representative images are shown at magnification $x 200$. ER- $\alpha$ /PR-positive cells were identified by brown staining in the cytoplasm. (A) ER- $\alpha$-negative and (B) ER- $\alpha$-positive tumor samples. (C) PR-negative and (D) PR-positive tumor samples. ER- $\alpha$, estrogen receptor- $\alpha$; PR, progesterone receptor. Scale bar, $100 \mu$ m.

Survival analysis of patients with early invasive ductal carcinoma with miR-10b (+) expression and different molecular subtypes. Patients that were miR-10b (+) with early invasive ductal carcinoma were divided into several molecular subtypes. These subtypes consisted of luminal A, luminal B, Her-2 overexpression and basal-like subtype. The Kaplan-Meier method and Log-rank test were used to perform survival analysis. The median disease-free survival time was 12.035 years for luminal A subtype, 9.882 years for luminal B subtype, 8.024 years for Her-2 overexpression subtype and 8.316 years for basal-like subtype. The median disease-free survival time of patients that were miR-10b (+) was significantly decreased in the Her-2 overexpression and basal-like subtypes compared with luminal A subtype $\left(\chi^{2}=8.340, P=0.039\right.$; Fig. 7). These data suggested that the positive expression of miR-10b was correlated with the median disease-free survival time of different molecular subtypes. 
A

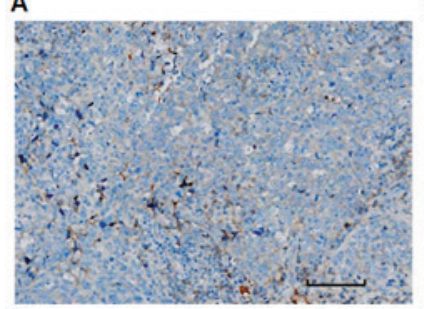

c

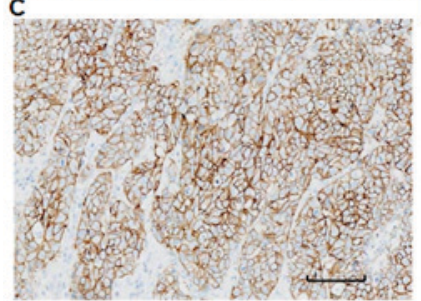

E

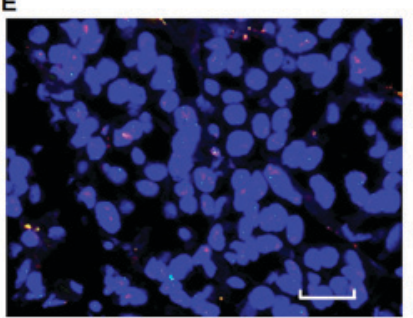

B

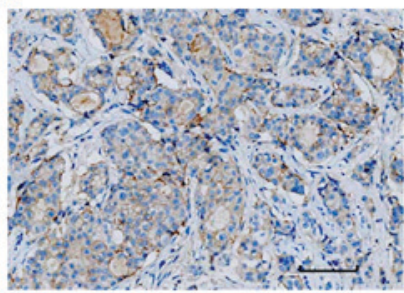

D

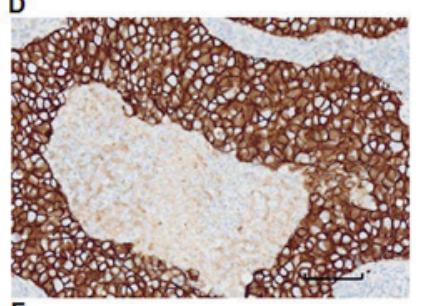

$\mathrm{F}$

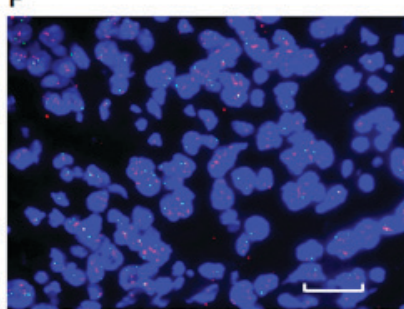

Figure 3. Her-2 expression in early invasive ductal carcinoma specimens detected by immunohistochemistry and FISHanalysis.Immunohistochemistry images were captured at magnification x200. (A-D) Grades of Her-2 expression. (A) Negative expression of Her-2 (-). (B) Weakly-positive expression of Her-2 (+). (C) Moderately-positive expression of Her-2 (++). (D) Strongly-positive expression of Her-2 (+++). FISH images were captured under a fluorescent microscope (magnification, x200). GLP HER-2/CSP17 fluorescent probes were used to label the centromere (green fluorescence) and Her-2 gene (orange fluorescence) in breast cancer samples. (E) Absence of Her-2 (fluorescence ratio <1.8). (F) Her-2 amplification (fluorescence ratio $>2.2$ ). FISH, fluorescence in situ hybridization; Her-2, human epidermal growth factor receptor. Scale bar, $100 \mu \mathrm{m}$.

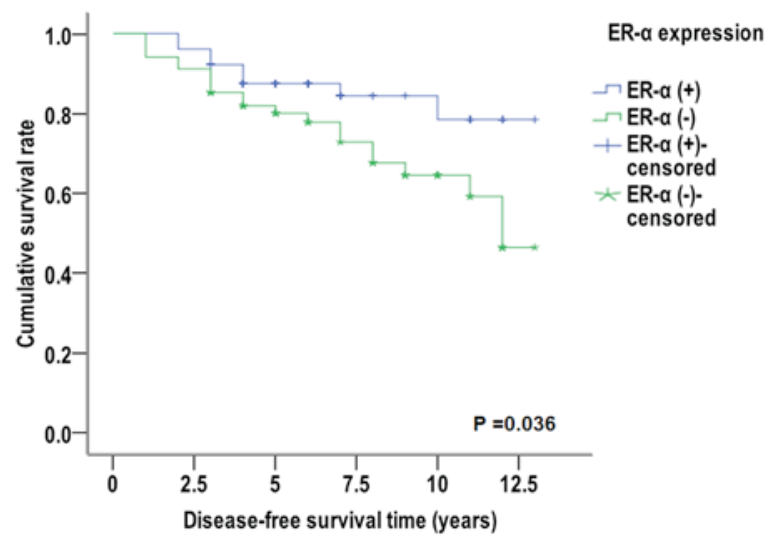

Figure 4. Survival analysis of patients with early invasive ductal carcinoma with miR-10b (+) expression and different expression levels of ER- $\alpha$. A Kaplan-Meier survival curve was constructed and the disease-free survival time of patients that were miR-10b (+) with different expression levels of ER- $\alpha$ was comparatively analyzed. miR-10B, microRNA-10b; ER- $\alpha$, estrogen receptor- $\alpha$. Censored group, group of 54/193 patients with normal-like immunohistochemistry results that were excluded.

Multivariate Cox regression analysis of the prognostic factors for patients with early invasive ductal carcinoma. To define

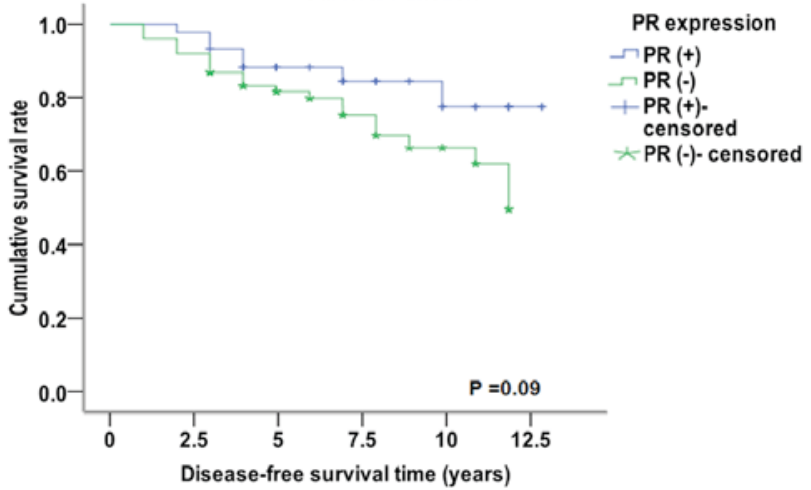

Figure 5. Survival analysis of patients with early invasive ductal carcinoma with miR-10 (+) expression and different expression levels of PR. A Kaplan-Meier survival curve was constructed and the disease-free survival time of patients that were miR-10 (+) with different expression levels of PR was comparatively analyzed. miR-10B, microRNA-10b; PR, progesterone receptor. Censored group, group of 54/193 patients with normal-like immunohistochemistry results that were excluded.

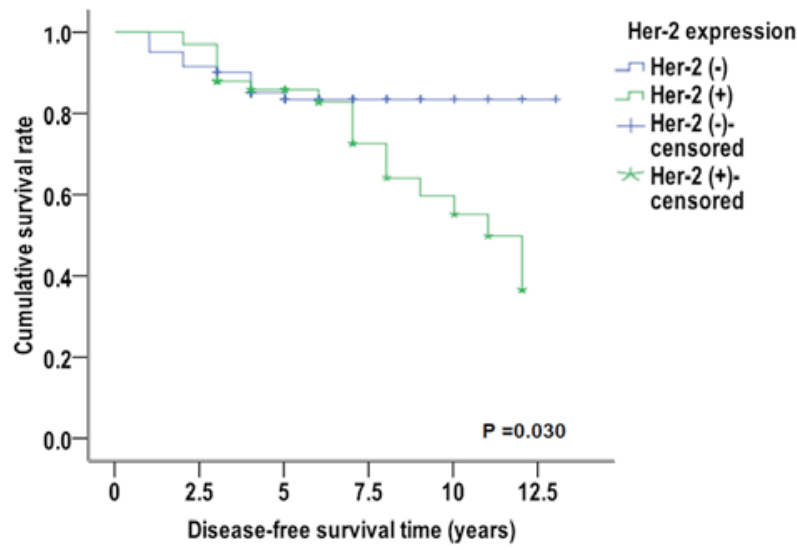

Figure 6. Survival analysis of patients with early invasive ductal carcinoma with miR-10 (+) expression and different expression levels of Her-2. A Kaplan-Meier survival curve was constructed and the disease-free survival time of patients that were miR-10 (+) with different expression levels of Her-2 was comparatively analyzed. miR-10B, microRNA-10b; Her-2, human epidermal growth factor receptor. Censored group, group of 54/193 patients with normal-like immunohistochemistry results that were excluded.

the prognostic factors of early invasive ductal carcinoma, multivariate Cox regression analysis was performed. The prognostic factors included menstruation, clinical stage, miR-10b expression, the molecular subtypes (luminal A, luminal B, Her-2 overexpression and basal-like subtype), chemotherapy and radiotherapy. Results indicated that the luminal A molecular subtype may be an independent prognostic factor for early breast invasive ductal carcinoma ( $\mathrm{P}=0.049$; Table IV). The basal-like and Her-2 overexpression subtypes were also identified as independent factors for poor prognosis [odds ratio $(\mathrm{OR})=5.232, \mathrm{P}=0.007$ and $\mathrm{OR}=4.214, \mathrm{P}=0.036$, respectively]. In addition, the expression of miR-10b may be a potential prognostic factor for early invasive ductal carcinoma $(\mathrm{OR}=3.339)$; though this was not statistically significant $(\mathrm{P}=0.108)$. These findings suggest that the molecular subtype may be an independent prognostic factor for early invasive ductal carcinoma of the breast. 
Table IV. Multivariate Cox regression analysis of early invasive ductal cancer molecular subtypes and prognostic factors.

\begin{tabular}{lcccccc}
\hline Clinicopathological variable & & $\begin{array}{c}\text { Standard } \\
\text { error }\end{array}$ & $\begin{array}{c}\text { Wald } \\
\text { value }\end{array}$ & P-value & OR & $\begin{array}{c}95 \% \text { confidence } \\
\text { interval }\end{array}$ \\
\hline Menstruation status (Entered menopause or not) & 0.171 & 0.409 & 0.174 & 0.676 & 1.186 & $0.532-2.645$ \\
Pathological grade (AJCC I or II) & 0.181 & 0.460 & 0.155 & 0.694 & 1.199 & $0.486-2.954$ \\
miR-10b & 1.206 & 0.749 & 2.589 & 0.108 & 3.339 & $0.769-14.507$ \\
Luminal A & - & - & 7.879 & 0.049 & - & - \\
Luminal B & 1.065 & 0.619 & 2.956 & 0.086 & 2.900 & $0.862-9.760$ \\
Basal-like & 1.655 & 0.610 & 7.366 & 0.007 & 5.232 & $1.584-17.283$ \\
Her-2 overexpression & 1.438 & 0.684 & 4.421 & 0.036 & 4.214 & $1.103-16.109$ \\
Chemotherapy (yes or no) & -0.394 & 1.065 & 0.137 & 0.711 & 0.674 & $0.084-5.433$ \\
Radiotherapy (yes or no) & 0.138 & 0.460 & 0.090 & 0.764 & 1.148 & $0.466-2.829$ \\
\hline
\end{tabular}

AJCC, American Joint Committee on Cancer; miR-10b, microRNA-10b; Her-2, human epidermal growth factor receptor-2; OR, odds ratio; $\beta, \beta$-coefficient. Luminal A served as the control group and the other groups (luminal B; triple negative; Her-2 over-expression) were compared with luminal A.

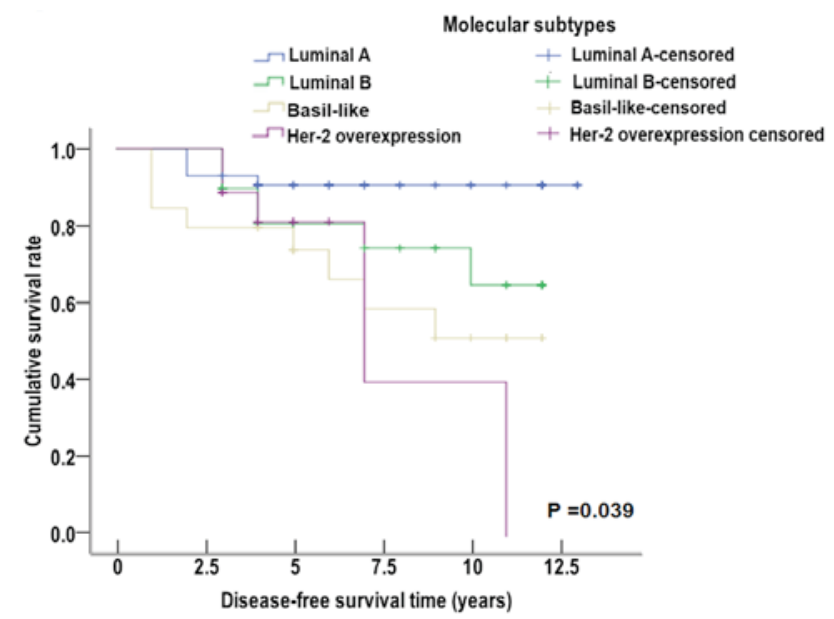

Figure 7. Survival analysis of patients with early invasive ductal carcinoma with miR-10 (+) expression and different molecular subtypes. A Kaplan-Meier survival curve was constructed and the disease-free survival time of patients that were miR-10 (+) with different molecular subtypes was comparatively analyzed. miR-10B, microRNA-10b; Her-2, human epidermal growth factor receptor; Censored group, group of 54/193 patients with normal-like immunohistochemistry results that were excluded.

\section{Discussion}

Invasive ductal carcinoma has been indicated as the most common pathological type of breast cancer, and accounts for $75 \%$ of all carcinomas of the breast $(24,25)$. Perou et al (5) and Sorlie et al (6) reported that breast cancer may be divided into four different subtypes (luminal A, luminal B, Her-2 overexpression and basal-like subtype) in accordance with the differential gene expression between tumor cells and normal cells. Lowery et al (15) further classified breast cancer subtypes based on their miRNA expression profiles and levels of ER- $\alpha$, PR and Her-2 expression. Lowery et al (15) also demonstrated that miRNA expression may be positively correlated with the expression levels of ER, PR and Her-2. Therefore, they proposed that breast cancer should be further divided according to the miRNA expression level, thus indicating that miRNA expression may be a diagnostic and prognostic indicator for breast cancer. To the best of our knowledge, no previous studies have investigated the association between miR-10b expression and the different molecular subtypes of breast cancer. The present results indicated that miR-10b expression was associated with the expression of ER- $\alpha$, PR, Her- 2 and the different molecular subtypes. The positive expression rate of miR-10b was significantly increased in patients that were ER- $\alpha$ (-) compared with those that were ER- $\alpha(+)$, and also significantly increased in patients that were Her-2 (-) compared with those that were Her-2 (+). These data indicated that miR-10b expression was negatively correlated with the expression of ER- $\alpha$ and Her-2. Furthermore, among the four distinct molecular subtypes of breast cancer, the positive expression rate of miR-10b in luminal $\mathrm{B}$ was the lowest, at $62.9 \%$. These data suggest that the expression of miR-10b potentially contributes to decreased expression of ER- $\alpha$ and Her-2, which may further lead to a reduced risk of recurrence and metastasis of the luminal B subtype. Notably, the present results indicated that elevated expression of ER- $\alpha$ may be a protective factor for breast cancer, whereas the upregulated expression of Her-2 may be a risk factor, and the non-luminal B subtypes, particularly Her-2 overexpression and basal-like, may increase the possibility of tumor recurrence and metastasis.

At present, studies have indicated different prognoses for the molecular subtypes of breast cancer. For instance, the luminal A subtype is the most common breast cancer subtype, and has been associated with a lower recurrence rate and an improved prognosis compared with all other subtypes $(3,26)$. The luminal B subtype is characterized by an upregulation in proliferation-associated genes, including CCNB1 and MYBL2, and genes associated with the signaling pathways of growth factor receptors (27). A previous study indicated that the percentage of histological grade III in luminal B was increased, despite lower expression levels of ER-related genes in the luminal B subtype (28). Furthermore, luminal $\mathrm{B}$ is less sensitive to endocrine therapy when compared with 
luminal A (29). The Her-2 overexpression subtype has the poorest prognosis among all the subtypes, potentially due to its higher secretion level of proteolytic enzymes (30), which stimulates cell division, enhances the invasive ability of tumor cells and promotes cancer metastasis $(6,31)$. The basal-like subtype typically occurs in pre-menopausal women, and ER- $\alpha$ (-), PR (-) and Her-2 (-) expression has been implicated in this subtype $(32,33)$. In addition, the basal-like subtype has been associated with a higher histological grade, poorer differentiation ability and stronger invasive capability compared with the other subtypes, which may result in early recurrence and distant metastasis $(11,12)$. In the present study, patients with miR-10b $(+)$ breast cancer with ER- $\alpha(+) / \mathrm{PR}$ $(+) / H e r-2(-)$ expression had a longer median disease-free survival time and improved prognosis, which was consistent with a previous study (8). Furthermore, results of the survival analysis (K-M curve) indicated that the luminal A subtype indicated the greatest prognosis in comparison with luminal B, basal-like subtype and Her-2 overexpression subtype. Among the latter, Her-2 overexpression had the shortest median survival time, indicating the poorest prognosis, and the result was in accordance with a previous study (6). In addition, miR-10b (-) expression had no effect on the median disease-free survival time of different breast cancer molecular subtypes (data not shown). There were 54 patients who showed normal-like results in the immunohistochemistry test and were therefore not categorized into the four subtypes, hence they were not analyzed in this study.

With advances in molecular biology, a molecular subtype theory has been proposed to explain the heterogeneity of breast cancer $(34,35)$, whereby different molecular subtypes of breast cancer may indicate different prognosis. For instance, the luminal A and B subtypes have been associated with an improved prognosis and lower rate of recurrence in comparison with subtypes Basal-like and Her-2 overexpression $(36,37)$. In addition, the Her-2 overexpression subtype has been associated with a poor prognosis, and patients that are Her-2-positive are suitable for targeted therapy (38). The basal-like subtype, which is characterized by ER- $\alpha(-)$, PR (-) and Her-2 (-), is typically associated with the poorest prognosis $(12,10)$. The present study indicated that the luminal A molecular subtype was also an independent prognostic factor in addition to basal-like and Her-2 overexpression. Furthermore, miR-10b (+) may be a risk factor for the prognosis of breast cancer.

In conclusion, the present study demonstrated that miR-10b expression was correlated with the expression of ER- $\alpha$, PR and Her-2, and the different breast cancer molecular subtypes. Furthermore, the different molecular subtypes of breast cancer indicated different prognoses. The present findings indicate that the expression of miR-10b may indirectly affect the prognosis of breast cancer.

\section{Acknowledgements}

The present work was supported by the Special Program for the Key Laboratory of Major Diseases and Medical Science of Xinjiang Autonomous Region, Co-constructing National Key Labs by Province and Ministry of Science and Technology of China (grant no. SKLI-XJMDR-ZX-2014-1).

\section{References}

1. Simpson PT, Reis-Filho JS and Lakhani SR: Breast pathology: Beyond morphology. Semin Diagn Pathol 27: 91-96, 2010.

2. Bevers TB, Anderson BO, Bonaccio E, Buys S, Daly MB Dempsey PJ, Farrar WB, Fleming I, Garber JE, Harris RE, et al: NCCN clinical practice guidelinesin oncology: Breast cancer screening and diagnosis. J Natl Compr Cancer Netw 7: 1060-1096, 2009.

3. Sorlie T, Tibshirani R, Parker J, Hastie T, Marron JS, Nobel A, Deng S, Johnsen H, Pesich R, Geisler S, et al: Repeated observation of breast tumor subtypes in independent gene expression data sets. Proc Natl Acad Sci USA 100: 8418-8423, 2003.

4. Goldhirsch A, Ingle JN, Gelber RD, Coates AS, Thürlimann B and Senn HJ; Panel members: Thresholds for therapies: Highlights of the St Gallen international expert consensus on the primary therapy of early breast cancer 2009. Ann Oncol 20: 1319-1329, 2009.

5. Perou CM, Sørlie T, Eisen MB, van de Rijn M, Jeffrey SS, Rees CA, Pollack JR, Ross DT, Johnsen H, Akslen LA, et al: Molecular portraits of human breast tumours. Nature 406: 747-752, 2000.

6. Sørlie T, Perou CM, Tibshirani R, Aas T, Geisler S, Johnsen H, Hastie T, Eisen MB, van de Rijn M, Jeffrey SS, et al: Gene expression patterns of breast carcinomas distinguish tumor subclasses with clinical implicatios. Proc Natl Acad Sci USA 98: 10869-10874, 2001.

7. Blenkiron C, Goldstein LD, Thorne NP, Spiteri I, Chin SF, Dunning MJ, Barbosa-Morais NL, Teschendorff AE, Green AR, Ellis IO, et al: MicroRNA expression profiling of human breast cancer identifies new markers of tumor subtype. Genome Biol 8: R214, 2007.

8. Zhang M, Mo J, Huang P, et al: Clinicopathologic profiles of breast cancer in young women: A report of 85 cases. Chinese Journal of General Surgery 23: 665-669, 2014.

9. Dent R, Hanna WM, Trudeau M, Rawlinson E, Sun P and Narod SA: Pattern of metastatic spread in triple-negative breast cancer. Breast Cancer Res Treat 115: 423-428, 2009.

10. Onitilo AA, Engel JM, Greenlee RT and Mukesh BN: Breast cancer subtypes based on ER/PR and Her2 expression: Comparison of clinicopathologic features and survival. Clin Med Res 7: 4-13, 2009.

11. Buzdar AU, Ibrahim NK, Francis D, Booser DJ, Thomas ES, Theriault RL, Pusztai L, Green MC, Arun BK, Giordano SH, et al: Significantly higher pathologic complete remission rate after neoadjuvant therapy with trastuzumab, paclitaxel, and epirubicin chemotherapy: Results of a randomized trial in human epidermal growth factor receptor 2-positive operable breast cancer. J Clin Oncol 23: 3676-3685, 2005.

12. Lund MJ, Butler EN, Bumpers HL, Okoli J, Rizzo M, Hatchett N, Green VL, Brawley OW, Oprea-Ilies GM and Gabram SG: High prevalence of triple-negative tumors in an urban cancer center. Cancer 113: 608-615, 2008.

13. Carrio M, Arderiu G, Myers C and Boudreau NJ: Homeobox D10 induces phenotypic reversion of breast tumor cells in a three-dimensional culture model. Cancer Res 65: 7177-7185, 2005.

14. Grøndahl-Hansen J, Christensen IJ, Briand P, Pappot H, Mouridsen HT, Blichert-Toft M, Dan $\varnothing \mathrm{K}$ and Brünner N: Plasminogen activator inhibitor type 1 in cytosolic tumor extracts predicts prognosis in low-risk breast cancer patients. Clin Cancer Res 3: 233-239, 1997.

15. Lowery AJ, Miller N, Devaney A, McNeill RE, Davoren PA, Lemetre C, Benes V, Schmidt S, Blake J, Ball G and Kerin MJ: MicroRNA signatures predict oestrogen receptor, progesterone receptor and HER-2/neu receptor status in breast cancer. Breast Cancer Res 11: R27, 2009.

16. Liu Z, Zhu J, Cao H, Ren H and Fang X: miR-10b promotes cell invasion through RhoC-AKT signaling pathway by targeting HOXD10 in gastric cancer. Int J Oncol 40: 1553-1560, 2012.

17. Ma L, Teruya-Feldstein J and Weinberg RA: Tumour invasion and metastasis initiated by microRNA-10b in breast cancer. Nature 449: 682-688, 2007.

18. Ujifuku K, Mitsutake N, Takakura S, Matsuse M, Saenko V, Suzuki K, Hayashi K, Matsuo T, Kamada K, Nagata I and Yamashita S: miR-195, miR-455-3p and miR-10a(*) are implicated in acquired temozolomide resistance in glioblastoma multiforme cells. Cancer lett 296: 241-248, 2010.

19. Biagioni F, Bossel Ben-Moshe N, Fontemaggi G, Canu V, Mori F, Antoniani B, Di Benedetto A, Santoro R, Germoni S, De Angelis F, et al: miR-10b*, a master inhibitor of the cell cycle, is down-regulated in human breast tumours. EMBO Mol Med 4: 1214-1229, 2012. 
20. Li Y, Wen J, Tang J, Lai M and Bu H: Breast Cancer Pathology, Eighth Edition-People's Medical Publishing House (China) 373-377, 2005

21. Wolff AC, Hammond ME, Schwartz JN, Hagerty KL, Allred DC, Cote RJ, Dowsett M, Fitzgibbons PL, Hanna WM, Langer A, et al: American society of clinical oncology/college of American pathologists guideline recommendations for human epidermal growth factor receptor 2 testing in breast cancer. Arch Pathol Lab Med 131: 18-43, 2007.

22. Prisack HB, Karreman C, Modlich O, Audretsch W, Danae M, Rezai $\mathrm{M}$ and Bojar $\mathrm{H}$ : Predictive biological markers for response of invasive breast cancer to anthracycline/cyclophos-phamide-based Primary (radio-)chemotherapy. Anticancer Res 25: 4615-4621, 2005.

23. Yarden Y: Biology of HER 2 and its importance in breast cancer. Oncology 61 (Suppl): S1-S13, 2001.

24. Stewart BW and Wild CP: World cancer report 2014. Int Age Res Can 28: 17-27, 2014

25. Chen W, Zheng R, Baade PD, Zhang S, Zeng H, Bray F, Jemal A Yu XQ and He J: Cancer statistics in China, 2015. CA Cancer J Clin 66: 115-132, 2016.

26. Yuan ZY, Wang SS, Zhu MQ, Zheng L, Luo WB, Zhou ZM and Guan ZZ: Clinical characteristics and prognosis of different subtypes of breast cancer. Zhonghua Zhong Liu Za Zhi 30: 456-461, 2008 (In Chinese).

27. Prat A and Perou C: Deconstructing the molecular portraits of breast cancer. Mol Oncol 5: 5-23, 2011.

28. Cheang MC, Chia SK, Voduc D, Gao D, Leung S, Snider J, Watson M, Davies S, Bernard PS, Parker JS, et al: Ki67 iddex, HER 2 status, and prognosis of patients with luminal B breast cancer. J Natl Cancer Inst 101: 736-750, 2009.

29. Wang $\mathrm{J}$ and $\mathrm{Wu} \mathrm{JH}$ : The clinical value of endocrine therapy for breast cancer in elderly women. J Can Cont Treat 23: 385, 2010.

30. Durbecq V, Ameye L, Veys I, Paesmans M, Desmedt C, Sirtaine N, Sotiriou C, Bernard-Marty C, Nogaret JM, Piccart M and Larsimont D: A significant proportion of elderly patients develop hormone-dependant 'luminal-B' tumours associated with aggressive characteristics. Crit Rev Oncol Hematol 67: 80-92, 2008
31. Onitilo AA, Engel JM, Greenlee RT and Mukesh BN: Breast cancer subtypes based on ER/PR and Her2 expression: Comparison of clinicopathologic features and survival. Clin Med Res 7: 4-13, 2009.

32. Jones PA and Baylin SB: The epigenomics of cancer. Cell 128 683-692, 2007.

33. Gee HE, Camps C, Buffa FM, Colella S, Sheldon H, Gleadle JM, Ragoussis J and Harris AL: MicroRNA-10b and breast cancer metastasis. Nature 455: E8-E9, 2008.

34. Green S, Walter P, Kumar V, Krust A, Bornert JM, Argos P and Chambon P: Human oestrogen receptor cDNA: Sequence, expression and homology to v-erb-A. Nature 320: 134-139, 1986.

35. Durbecq V, Ameye L, Veys I, Paesmans M, Desmedt C, Sirtaine N, Sotiriou C, Bernard-Marty C, Nogaret JM, Piccart M and Larsimont D: A significant proportion of elderly patients develop hormone-dependant 'luminal-B' tumours associated with aggressive characterristics. Crit Rev Oncol Hematol 67: 80-92, 2008.

36. Winer EP, Hudis C, Burstein HJ, Wolff AC, Pritchard KI, Ingle JN, Chlebowski RT, Gelber R, Edge SB, Gralow J, et al: American Society of Clinical Oncology technology assessment on the use of aromatase inhibitors as adjuvant therapy for postmenopausal women with hormone receptor-positive breast cancer: Status report 2004. J clin Oncol 23: 619-629, 2005.

37. Bartlett JM, Ellis IO, Dowsett M, Mallon EA, Cameron DA, Johnston S, Hall E, A'Hern R, Peckitt C, Bliss JM, et al: Human epidermal growth factor receptor 2 status correlates with lymph node involvement in patients with estrogen receptor (ER) negative, but with grade in those with ER-positive early-stage breast cancer suitable for cytotoxic chemotherapy. J Clin Oncol 25: 4423-4430, 2007.

38. Yang Q, Chen J, Li HJ, Yu M, Tian CX and Lü Q: Clinical features and prognosis analysis of different breast cancer molecular subtypes. Zhonghua Zhong Liu Za Zhi 33: 42-46, 2011 (In Chinese).

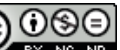

This work is licensed under a Creative Commons Attribution-NonCommercial-NoDerivatives 4.0 International (CC BY-NC-ND 4.0) License. 